Rodrigues, L. A., Oliveira, M. O. R. \& Medeiros, N. C. L. (2017). Análise sistemática da evolução conceitual do comportamento de compra impulsiva. Consumer Behavior Review, 1(2), 82-91.

ISSN: 2526-7884

Editor: Prof. Dr. Marconi Freitas da Costa Email da revista: cbr@ufpe.br
Avaliação: Double blind review Recebido: 01 de março de 2017 Aceito: 18 de setembro de 2017

\title{
ANÁLISE SISTEMÁTICA DA EVOLUÇÃO CONCEITUAL DO COMPORTAMENTO DE COMPRA IMPULSIVA
}

\author{
Luis Adriano Rodrigues \\ Marta Olivia Rovedder de Oliveira \\ Natane Cassia Leivas de Medeiros
}

Luis Adriano Rodrigues é Mestrando em Administração, Universidade Federal de Santa Maria - UFSM. E-mail:

luisadriano@bol.com.br.

Marta Olivia Rovedder de Oliveira é

Professora do Programa de Pós-Graduação em Administração, Universidade Federal de Santa Maria - USFM. E-mail:

marta.oliveira@ufsm.br.

Natane Cassia Leivas de Medeiros é

Mestranda em Administração pela

Universidade Federal de Santa Maria -

UFSM. E-mail: natanemedeiros@gmail.com.

Os autores agracedecem aos avaliadores

pelos comentários para melhoria do artigo.

\begin{abstract}
Resumo
O comportamento de compra impulsiva sofreu várias alterações em sua conceituação ao longo do tempo, e essa pesquisa visa compreender como ele foi compreendido e o que as principais pesquisas dos últimos dez anos vêm encontrando de relevante em seus resultados para melhor compreensão do assunto. A pesquisa ocorre de forma quantitativa e qualitativa, a partir de um levantamento da base de dados Scopus ${ }^{\circledR}$ entre o período de 2005 e 2014, sobre compra impulsiva e de uma análise descritiva dos dados encontrados, via o uso do software Nvivo 10®. Entre os resultados, o método de pesquisa mais utilizado nesse assunto é a survey. Além disso, o presente estudo demonstra que a conceituação do que se compreende como comportamento de compra impulsiva sofreu diversas alterações ao longo do tempo.

Palavras-chave: Bibliometria; Comportamento de compra; Compra impulsiva.
\end{abstract}

Esta obra está licenciada com uma Licença Creative Commons Atribuição 4.0 Internacional.

\section{INTRODUÇÃO}

Historicamente, os estudos sobre compra impulsiva surgiram em meados dos anos 50 (Piron, 1991), através dos interesses gerenciais, em benefício dos setores varejistas (Youn \&
Faber, 2000). Há mais de 70 anos, grande parte das investigações sobre compras impulsivas focam nos aspectos situacionais que afetam o impulso da compra (Beatty \& Ferrell, 1998). Os primeiros estudos relacionavam a compra por 
impulso com a compra não planejada, por se tratar de uma compra diferente da habitual, em que o consumidor já tem uma predefinição do que pretende comprar antes de chegar à loja (Bellenger, Robertson \& Hirschamn, 1978; Kollat \& Willet, 1967; Stern, 1962). Desse modo, esses estudos investigaram apenas a compra, mas não o consumidor, dado que os interesses estavam voltados na difusão da compra por impulso e na identificação das diferenças entre as compras reais e planejadas (Piron, 1991). Entretanto, estudos como Rook e Hoch (1985), Beatty e Ferrell (1998), Youn e Faber (2000) buscaram aprofundar o que até então era entendido como compra impulsiva.

$\mathrm{Na}$ visão de Rook e Hoch (1985), ao classificar uma compra em impulsiva, os fatores cognitivos também devem ser considerados, uma vez que a compra não planejada pode ter sido desencadeada por meio de uma memória do cliente, que foi despertada ao visualizar determinado item que está em falta na sua despensa. Para tanto, os autores classificam as compras não planejadas em impulsivas e não impulsivas.

Stern (1962) identificou que há quatro tipos diferentes de compra por impulso: a compra por impulso pura, que ocorre quando é apenas a impulsividade gerada na compra; a impulsividade por recordação, que ocorre quando a pessoa é influenciada por algo do passado como a marca que a mãe utilizava; compra por sugestão, que ocorre quando outra pessoa ou situação influencia o ato; e a compra por impulso planejada, que ela já tinha intenção de comprar. Esses constructos são avaliados e testados de várias formas diferentes, onde há concordâncias e discordâncias dos mesmos.

Já os autores Beatty e Ferrell (1998) defendem que a compra por impulso não é o mesmo que compra não planejada. Afirmam que, durante a primeira, o cliente não tinha a intenção de comprar. Logo, não se trata de um lembrete simples sobre algum produto que necessite, mas sim, de algo espontâneo, junto com uma vontade irresistível, sem consideração plena das suas consequências.

0 estudo de Youn e Faber (2000) busca avaliar além do conceito da compra por impulso apresentado até aqui. Os autores tentam desvendar a relação entre a tendência da compra por impulso e três dimensões de traços de personalidade primária, tais como: Falta de controle (ou impulsividade), reação ao estresse, e absorção.

No presente artigo, identificou-se que a compra por impulso tem sido uma área amplamente estudada, onde os autores têm buscado aprimorar os conceitos e identificar as variáveis que afetam este tipo de comportamento. Todavia, com relação ao Brasil, os estudos sobre compra impulsiva ainda são tímidos, tendo em vista que a maioria dos autores responsáveis pelos principais conceitos abordados é internacional (Da Costa \& Larán, 2006). Nesse sentido, o estudo tem por finalidade realizar uma análise sistemática da literatura com o objetivo de compreender as pesquisas realizadas sobre o tema e como a conceituação e interpretação evoluiu com o tempo.

Para tanto, este trabalho encontra-se subdividido da seguinte maneira: após a presente introdução, apresenta-se o referencial teórico utilizado com o intuito de promover o embasamento para a realização da pesquisa, contemplando uma breve evolução dos estudos e conceitos referentes à compra impulsiva. $\mathrm{Na}$ sequência, exibem-se os métodos utilizados para a elaboração da pesquisa e as respectivas etapas adotadas para o alcance dos objetivos traçados. Em seguida, a análise e discussão dos resultados. Por fim, têm-se as considerações finais a partir do estudo realizado.

\section{COMPRA POR IMPULSO}

A compra impulsiva pode ser caracterizada como uma vontade súbita e poderosa que age sobre o consumidor, induzindo-o a comprar imediatamente (Beatty \& Ferrell, 1998). Em muitos casos, as pessoas sentem que os desejos ativados pelo impulso precisam ser satisfeitos agora ou nunca (Rook \& Hoch, 1985). Neste sentido, Lins e Pereira (2011) corroboram que a compra por impulso se diferencia dos demais tipos de comportamento de compra devido à rapidez com que a decisão do consumidor acontece, logo, afirmam que quanto mais rápida for a definição de aquisição, maior será a impulsividade da compra.

Em consonância com as abordagens apresentadas, Mukhopadhyay, Sengupta e Ramanathan (2008) definem o comportamento impulsivo como uma vontade súbita e não planejada, que ocorre de maneira prazerosa e 
agradável, sendo imediatamente gratificante, em que o indivíduo age impulsivamente, descuidando das possíveis consequências destes atos. Afirma ainda que o comportamento impulsivo se manifesta quando o consumidor deseja adquirir espontaneamente um item que foge da sua realidade financeira, atraído por um forte desejo instantâneo.

Em contrapartida, para Rook e Hoch (1985) a compra por impulso vai além do simples conceito de compra não planejada, podendo ser distinguida através de 5 características: 1 desejo súbito de aquisição do item; 2 - estado de desequilíbrio psicológico, ou ausência de controle; 3 - conflito psicológico e luta - fatores emocionais são dominantes; 4 - diminuição da avaliação cognitiva; 5 - agir desconsiderando as possíveis consequências.

Beatty e Ferrel (1998) concordam em parte com Rook e Hoch (1985), pois definem que a compra por impulso acontece repentinamente sem apresentar nenhuma intenção précomercial. As características "não intencional" e "não planejada" têm sido associadas à compra por impulso em diversos estudos, apresentando-se como uma base necessária para compreender este fenômeno, mas ainda não é suficiente para caracterizar uma compra como impulsiva (Kollat \& Willet, 1967; Rook, 1987; Rook \& Fisher, 1995; Jones et al, 2003).

O comportamento impulsivo ocorre depois de experimentar um desejo de comprar algo, espontaneamente e sem muita reflexão. Deste modo, não inclui a compra de itens de lembrete simples, ou seja, itens relacionados ao estoque de casa. $\mathrm{Na}$ visão dos autores, a compra impulsiva ocorre quando o cliente não tinha a intenção de adquirir determinado produto antes de entrar na loja (Beatyy \& Ferrell, 1998).

A Figura 1 demonstra como foi modificada a conceituação de compra por impulso ao longo dos anos entre 1945 e 1989.

A conceituação do que se compreende como sendo comportamento de compra impulsiva, sofreu diversas alterações entre o período de 1945 e 1989. Na figura 1 estão destacadas as principais pesquisas realizadas na área, sendo que em alguns períodos a compreensão da conceituação, como pode ser observada, é muito semelhante a outros períodos. Tal período, de 1945 a 1989, foi escolhido para a análise como forma de compreensão do estado do conhecimento no seu passado e para comparálo aos dados atuais.

Em muitos casos, a compra por impulso pode ocorrer por meio de uma mudança nos hábitos rotineiros, onde o consumidor recorda-se de uma necessidade ou uma oferta atraente enquanto está andando pelos corredores de uma loja. Pode ocorrer também, pelo impulso provocado ao visualizar um produto desconhecido, então o consumidor o assimila como necessário e útil naquele momento. Nesse sentido, a compra por impulso mais tipicamente estudada até hoje, ocorre quando o consumidor é induzido por um apelo de merchandising na loja e acaba comprando algum produto ou serviço sem ter planejado (Araújo \& Ramos, 2007).

O estudo desenvolvido por Beatty e Ferrell (1998) apontou uma relação positiva entre a disponibilidade de dinheiro e compra por impulso. Deste modo, quando os consumidores se encontram com menos renda disponível, ficam menos propensos a realizar compras por impulso. Embora a compra por impulso nem sempre seja oriunda da ausência de planejamento, o uso de ferramentas como lista de compras diminui a probabilidade de se realizar compras por impulso (Hampson \& McGoldrick, 2013).

A súbita vontade de comprar pode colocar o consumidor em um estado de desequilíbrio psicológico, onde o indivíduo sente-se temporariamente fora de controle. A tentação promovida por este impulso de consumo pode ameaçar a vida de uma pessoa, afetando seu orçamento, sua dieta, sua programação, ou reputação. Entende-se que o consumidor é tentado em duas direções e precisa pesar os benefícios da gratificação imediata proporcionada por aquela compra, contra as possíveis consequências a longo prazo que pode resultar. Vale salientar que nem todos os impulsos de compra necessariamente envolvem este tipo de conflito (Rook \& Hoch, 1985).

Na visão de Almeida e Jolibert (1993), os estudos podem ser classificados em três tipos, conforme a variedade dos temas abordados: quando a compra impulsiva é considerada uma compra não planejada, em que a principal causa deve-se ao meio ambiente, esta pode ser classificada como tradicional. Para os casos em que a compra impulsiva é vista como uma compra emocional, trata-se de um tipo chamado 
comportamental simples. Já para os casos em que a compra impulsiva é percebida como uma doença devido à dependência psicológica do consumidor, esta pode ser classificada como comportamental exagerada. A partir destes conceitos, é possível comparar a compra por impulso com a compra compulsiva.

Entretanto, a compra impulsiva não deve ser considerada uma doença, mas um hábito de consumo da era moderna (Wood, 1998). Deste modo, a compra por impulso se diferencia da compulsividade, pois a primeira está ligada a um fator externo, quando um determinado produto estimula o indivíduo a comprar. Já a compulsividade está vinculada a fatores internos, muitas vezes sendo uma resposta primária a sentimentos negativos, ou buscando compensar algum distúrbio de ansiedade, além de tornar-se crônica e repetitiva (Faber, 2000).

\section{MÉTODO}

A pesquisa se classifica como qualitativa no que se refere à análise de conteúdo dos artigos encontrados e também como revisão sistemática, identificando o método, autores, ano de publicação e os seus resultados, e quantitativa no que se refere ao levantamento de dados relevantes a quantidade de resultados. A pesquisa foi feita na base de dados Scopus ${ }^{\circledR}$, onde se buscou entre o período de 2005 e 2014 os artigos referentes ao tema, como é exposta na análise dos dados. Identificar, mapear e analisar trabalhos acadêmicos publicados sobre determinado tema através de revisões sistemáticas é uma maneira de avaliar e refletir sobre estes trabalhos e sobre a área em estudo, permitindo diagnosticar indicadores, tendências e vieses da referida área. Estas revisões, em geral, são realizadas por meio de técnicas como a análise bibliométrica (Cardoso et al., 2005). A bibliometria consiste no estudo dos aspectos quantitativos da produção (Macias-Chapula, 1998), por meio das publicações em livros, relatórios e artigos (Ferreira, 2011).

0 universo de estudo contempla 50 artigos, levantados através do indexador Scopus ${ }^{\circledR}$ devido ao seu grande número de periódicos indexados. Para garantir que a busca contemplasse todos os papers relacionados ao tema, utilizou-se as palavras-chave "impulsive purchase" e "Compra impulsiva", utilizando o termo boleano "and" entre os termos buscados.

Foram encontrados 50 resultados, sendo que estão divididos nas áreas de business, management and accounting (Negócios, Gestão e Contabilidade) com 37 resultados, na área de Economics, Econometrics and Finance (Econômicas, Econométricas e Finanças) com 12 resultados, e 12 resultados na área de Psychology (Psicologia), levando em consideração que alguns artigos se enquadram em duas ou mais áreas simultaneamente.

A análise dos dados ocorreu de forma descritiva, utilizando-se dos softwares Nvivo $10 ®$ para a análise de conteúdo dos artigos em relação aos termos encontrados, com o auxílio do Microsoft Excel® para a tabulação dos estudos dos artigos analisados.

\section{ANÁLISE DOS RESULTADOS}

Os principais trabalhos que abordaram as pesquisas de compra impulsiva encontrados nesse levantamento estão apresentados em um quadro, disponível no apêndice. Para selecionar quais artigos seriam analisados, foram selecionados aqueles que possuíam maiores quantidades de citações de cada ano, que melhor se encaixavam no foco da pesquisa e que possuíam características consideradas como relevantes para o assunto, segundo os resultados encontrados na base de dados Scopus ${ }^{\circledR}$, removendo artigos que não tinham como foco "compra impulsiva" e que os termos apenas apareciam nos estudos como parte da construção do referencial teórico.

Com este levantamento é possível observar as diversas formas que o comportamento de compra impulsivo vem sendo estudado em todo o mundo, sob os mais diversos aspectos $\mathrm{e}$ diferentes sujeitos estudados. Tais objetos de estudo com foco em comportamento do consumidor, referente ao comportamento de compra impulsivo, pode variar dependendo do foco dentro dessa área. Entre os 50 artigos analisados, as metodologias utilizadas para o estudo foram as seguintes:

Através dessa análise é possível se observar que a palavra que teve maior incidência nos artigos analisados foi a palavra "consumer" com 906 ocorrências, com $0,86 \%$ do percentual ponderado, "Buyng" com 660 ocorrências, representando 0,63\%, "consumers" com 0,59\% e 
626 resultados, sendo que "impulse" foi a quarta palavra com maior ocorrência, com 603 resultados, com $0,58 \%$ do percentual ponderado.

Através da análise das pesquisas realizadas até o momento foi possível identificar que a compra impulsiva ocorre em detrimento de fatores internos e externos, ocorrendo de forma simultânea. Partindo disso, o quadro 4 demonstra características encontradas nas pesquisas que podem influenciar o consumidor na hora da compra.

0 estímulo ao efetuar uma compra de forma impulsiva está, além disso, ligado a fatores situacionais, como o dinheiro disponível para efetuar a compra, assim como características que o produto possui. Tais aspectos se tornam relevantes ao serem encontrados simultaneamente com outros fatores internos e externos, e dessa forma havendo a compra impulsiva.

\section{CONSIDERAÇÕES FINAIS}

As pesquisas na área do comportamento do consumidor, em especial sobre o comportamento de compra impulsivo, são de extrema relevância para a compreensão de como as organizações podem se utilizar de tais estudos para formular estratégias para alavancar as suas vendas. A pesquisa demonstra que a conceituação do que se compreende como comportamento de compra impulsiva sofreu diversas alterações ao longo do tempo.

Conforme é observado nesta pesquisa, o comportamento de compra impulsivo já foi considerado como sendo uma doença, assim como outros aspectos que assim também foram classificados, mas que ao longo do tempo foram sendo alterados, com base em pesquisas feitas na área, ou até em outras áreas de pesquisa, e hoje pode ser considerado como um fator psicológico. A principal compreensão sobre o conceito do que pode ser considerado como uma compra impulsiva, é que é "uma compra não planejada" pela maioria dos autores.

A pesquisa feita no cunho de levantamento bibliométrico, com base nos dados levantados, após a sua análise podemos compreender como as pesquisas vêm sendo realizadas, aplicação de métodos, escalas que foram aplicadas, principais autores que estão trabalhando com essas pesquisas, quais pesquisas são mais relevantes na área nos últimos dez anos, assim como outros fatores que podem auxiliar na escolha do método da pesquisa a ser utilizado em futuras pesquisas.

Entre as limitações de pesquisa se encontra o fato de ter sido feita em apenas uma base de dados. Para futuras pesquisas, recomenda-se fazer em outras bases, excluindo os artigos que se repetem e, se possível, fazer uma relação social dos autores que estão trabalhando com comportamento impulsivo.

Com essa pesquisa pode-se concluir que o método mais utilizado para pesquisa na área é o survey, seguido do experimento em segundo lugar. Ao se fazer uma análise sobre os termos que mais aparecem nesses artigos, o termo mais utilizado é "consumer", sendo que a maioria dos artigos (37 artigos) são da área de Business. Na maioria dos experimentos, o local de aplicação foi em ambientes de shopping.

Há a necessidade de se utilizar da ligação com outras áreas para a compreensão do assunto, pois em apenas um dos trabalhos a neurociência foi utilizada. A pesquisa demonstra que pesquisadores de diferentes áreas, ainda que sejam poucas, atuam comumente na busca da compreensão de como ocorre a compra impulsiva. A Compra impulsiva é mais aceita pela academia, assim como os resultados encontrados nessa pesquisa, como sendo um fator psicológico.

A pesquisa pretende direcionar pesquisadores na área para novas metodologias de pesquisa, e a busca por novos resultados ou comprovação dos mesmos, e sugere que novos pesquisadores trabalhem com duas ou mais áreas de pesquisa simultaneamente para a maior compreensão sobre o comportamento de compra impulsiva.

\section{REFERÊNCIAS}

Beatty, S. E., \& Ferrell, M. E. (1998). Impulse buying: Modeling its precursors.Journal of retailing, 74(2), 169-191.

Bellenger, D. N., Robertson, D. H., \& Hirschman, E. C. (1978). Impulse buying varies by product.Journal of Advertising Research, 18(6), 15-18.

Cardoso, R. L., de Mendonça Neto, O. R., Riccio, E. L., \& Sakata, M. C. G. (2005). Pesquisa científica em contabilidade entre 1990 e 2003. RAE - 
Revista de Administração de Empresas, 45(2), 34-45.

Da Costa, F. C. X., \& Larán, J. A. (2006). Influências do ambiente de loja e o comportamento de compra por impulso: a visão dos clientes de lojas virtuais. Revista de Administração, 41(1), 96-106.

De Almeida, S. T., \& Jolibert, A. (1993). A influência do humor sobre a compra impulsiva. Revista de Administração, 28(4).

De Araújo, G. P., \& Ramos, A. S. M. (2010). Comportamento de compra por impulso em shopping centers: pesquisa com consumidores de Brasília-DF e NatalRN. Revista Eletrônica de Administração, 16(3), 589-610.

Daniel, P., \& McGoldrick, P. J. H. (2012). A typology of adaptive shopping patterns in recession. Journal of Business Research, 66(7), 831-838.

Faber, R. J. (2000). A systematic investigation into compulsive buying. In: A. L. Benson e J. Aronson. I shop therefore I am: Compulsive buying and the search for self. 1, 27-53.

Jones, M. A., Reynolds, K. E., Weun, S., \& Beatty, S. E. (2003). The product-specific nature of impulse buying tendency. Journal of Business Research, 56(7), 505-511.

Kollat, D. T., \& Willett, R. P. (1967). Customer impulse purchasing behavior.Journal of Marketing Research, 21-31.

Lins, S. L. B., \& de Faria Pereira, R. D. C. (2011). Comprou sem querer? Entenda o porquê! Revista Brasileira de Gestão de Negócios, 13(41), 376.
Macias-Chapula, C. A. (1998). O papel da informetria e da cienciometria e sua perspectiva nacional e internacional. Ciência da informação, 27(2), 134-140.

Mukhopadhyay, A., Sengupta, J., \& Ramanathan, S. (2008). Recalling past temptations: An information-processing perspective on the dynamics of self-control. Journal of Consumer Research, 35(4), 586-599.

Piron, F. (1991). Defining impulse purchasing. Advances in Consumer Research, 18.

Ferreira, M. P. (2011). A bibliometric study on Ghoshal's managing across borders. Multinational Business Review, 19(4), 357-375.

Rook, D. W., \& Hoch, S. J. (1985). Consuming impulses. Advances in Consumer Research, 12.

Rook, D. W. (1987). The buying impulse. Journal of Consumer Research, 14(2), 189-199.

Rook, D. W., \& Fisher, R. J. (1995). Normative influences on impulsive buying behavior. Journal of Consumer Research, 22(3), 305-313.

Stern, H. (1962). The significance of impulse buying today. Journal of Marketing, 59-62.

Wood, M. (1998). Socio-economic status, delay of gratification, and impulse buying. Journal of Economic Psychology, 19(3), 295-320.

Youn, S., \& Faber, R. J. (2000). Impulse buying: its relation to personality traits and cues. Advances in Consumer Research, 27.

\title{
Systematic Analysis of the Conceptual Evolution of Impulsive Buying Behavior
}

\begin{abstract}
Impulsive buying behavior has undergone several changes in its conceptualization over time, and this research aims to understand how it was understood, and what the main researches of the last ten years have been finding in their results, which make it relevant for the Understanding of the subject. The research takes place in a quantitative and qualitative way, making a survey of the Scopus ${ }^{\circledR}$ database between the period of 2005 and 2014, on impulse buying and a descriptive analysis of the data found through the use ofthe Nvivo 10® software. Among the results, the most used research method in this subject is the survey. In addition, the present study demonstrates that the conceptualization of what is understood as impulsive buying behavior has undergone several changes over time.
\end{abstract}

Keywords: Bibliometric, Behavior of purchase, Impulse buying. 


\section{Apêndice}

\section{Principais pesquisas sobre compra impulsiva 2005 a 2014}

\begin{tabular}{|c|c|c|}
\hline Referências & Objetivo/Método & Principais resultados \\
\hline Luo (2005) & $\begin{array}{l}\text { O método para essa pesquisa foram } \\
\text { dois experimentos realizados pelo } \\
\text { autor, com estudantes no ambiente } \\
\text { de shoppings, onde, através dos } \\
\text { métodos utilizados, o autor sugere } \\
\text { que o comportamento impulsivo } \\
\text { pode aumentar quando o indivíduo } \\
\text { se encontra com outro indivíduo, } \\
\text { ou seja, um experimento com } \\
\text { indivíduos divididos em duplas. }\end{array}$ & $\begin{array}{l}\text { Através do experimento, o autor } \\
\text { identificou o aumento de compras } \\
\text { impulsivas por pessoas que } \\
\text { estavam em pares ou em grupos no } \\
\text { ambiente de compra, porém, } \\
\text { quando o mesmo indivíduo é } \\
\text { colocado no mesmo ambiente com } \\
\text { membros da sua família, o } \\
\text { comportamento de compra } \\
\text { impulsiva é reduzido. }\end{array}$ \\
\hline Morrin e Chebat (2005) & $\begin{array}{l}\text { Esse estudo realizado com } 774 \\
\text { pessoas tem como foco principal } \\
\text { identificar as características nos } \\
\text { ambientes de compra que } \\
\text { influenciam o consumidor ter } \\
\text { comportamento de compra } \\
\text { impulsiva, o método utilizado pelos } \\
\text { autores foi de survey. }\end{array}$ & $\begin{array}{l}\text { No estudo foram encontradas } \\
\text { diversas características que } \\
\text { influenciam na compra impulsiva, } \\
\text { entre elas a quantidade de batidas } \\
\text { por minuto da música que está } \\
\text { sendo tocada no ambiente, quanto } \\
\text { maior o nível de informações sobre } \\
\text { o produto e mais contemplativo for } \\
\text { o ambiente, assim como as placas } \\
\text { utilizadas para demonstrar os } \\
\text { preços dos produtos. }\end{array}$ \\
\hline Peck e Childers (2006) & $\begin{array}{l}\text { A pesquisa tem como foco } \\
\text { examinar a influência do tocar o } \\
\text { produto e a compra impulsiva, para } \\
\text { isso os autores replicaram o estudo } \\
\text { de Rook e Fisher. }\end{array}$ & $\begin{array}{l}\text { Como resultado do estudo os } \\
\text { autores identificaram uma relação } \\
\text { direta em tocar o produto e os } \\
\text { fatores do ambiente com o } \\
\text { comportamento de compra } \\
\text { impulsiva. }\end{array}$ \\
\hline $\begin{array}{l}\text { Zhang, Prytubok e Strutton } \\
\text { (2007) }\end{array}$ & $\begin{array}{l}\text { O artigo tem como objetivo de } \\
\text { pesquisa identificar questões que } \\
\text { possam influenciar em compras } \\
\text { online, a pesquisa se deu através de } \\
\text { questionários. }\end{array}$ & $\begin{array}{l}0 \text { artigo demonstrou que o uso do } \\
\text { cartão de crédito nesse ambiente } \\
\text { até o momento deveria ser mais } \\
\text { amplamente estudado e } \\
\text { implantado para facilitar os meios } \\
\text { de pagamentos, assim como } \\
\text { elementos no design do site de } \\
\text { compra, essa pesquisa foi pioneira } \\
\text { no comportamento impulsivo com } \\
\text { o uso de meios eletrônicos de } \\
\text { compra. }\end{array}$ \\
\hline $\begin{array}{l}\text { Stravinskienė, Rūtelionė e } \\
\text { Butkevičienė (2008) }\end{array}$ & $\begin{array}{l}\text { Os autores têm como objetivo fazer } \\
\text { uma análise entre os fundamentos } \\
\text { teóricos e os resultados empíricos } \\
\text { sobre as informações no pacote ao } \\
\text { consumidor no seu processo de } \\
\text { decisão de consumo, a metodologia } \\
\text { utilizada foi a de questionários. }\end{array}$ & $\begin{array}{l}\text { Como conclusão, os autores } \\
\text { identificaram que o pacote é o mais } \\
\text { importante item para a tomada de } \\
\text { decisão na compra de um produto. }\end{array}$ \\
\hline Kim, Yang e Lee (2009) & $\begin{array}{l}\text { Esse estudo tem como objetivo } \\
\text { fazer uma comparação das } \\
\text { diferenças culturais de compra da } \\
\text { criação caucasiana canadense e a } \\
\text { criança chinesa canadense, o } \\
\text { método utilizado para a pesquisa } \\
\text { foi o de questionários. }\end{array}$ & $\begin{array}{l}\text { Das oito categorias analisadas } \\
\text { nessa pesquisa, somente duas } \\
\text { obtiveram diferenças notórias na } \\
\text { forma de percepção da compra } \\
\text { pelas crianças, onde o grupo com } \\
\text { um longo tempo de residência no } \\
\text { Canadá não levou em consideração }\end{array}$ \\
\hline
\end{tabular}




\begin{tabular}{|c|c|c|}
\hline & & $\begin{array}{l}\text { o status do valor da marca e nem } \\
\text { tem comportamento compulsivo } \\
\text { em relação aos demais. }\end{array}$ \\
\hline $\begin{array}{l}\text { Herabadi, Verplanken e } \\
\text { Knippenberg (2009) }\end{array}$ & $\begin{array}{l}\text { Para esse estudo foram usados dois } \\
\text { métodos para identificar os fatores } \\
\text { de compra impulsiva. No primeiro } \\
\text { estudo, em um shopping, } \\
\text { imediatamente após a compra } \\
\text { pelos sujeitos analisados, foram } \\
\text { realizadas entrevistas com os } \\
\text { consumidores para identificar os } \\
\text { fatores que poderiam influenciar o } \\
\text { seu comportamento na compra, e } \\
\text { no estudo dois, foi feito um diário } \\
\text { de compras de dois meses com } \\
\text { estudantes de uma universidade } \\
\text { para verificar o seu } \\
\text { comportamento dentro desse } \\
\text { período. }\end{array}$ & $\begin{array}{l}\text { No método um, foi feito um } \\
\text { levantamento dos sentimentos dos } \\
\text { consumidores após a compra, } \\
\text { sendo que a mesma análise foi feita } \\
\text { para o estudo dois, após a análise } \\
\text { os valores foram cruzados para } \\
\text { identificar não somente fatores } \\
\text { afetivos, e sim cognitivos, para } \\
\text { identificar os interesses dos } \\
\text { consumidores. }\end{array}$ \\
\hline Leng e Botelho (2010) & $\begin{array}{l}\text { Esse artigo tem como foco fazer } \\
\text { uma análise da cultura nacional } \\
\text { entre o Brasil, Japão e Estados } \\
\text { Unidos na decisão de compra de } \\
\text { smartphones, a metodologia para } \\
\text { esse trabalho foram questionários. }\end{array}$ & $\begin{array}{l}\text { A pesquisa teve como cunho fazer } \\
\text { uma análise da diferença entre as } \\
\text { três culturas perante a compra de } \\
\text { smartphones. Nessa pesquisa foram } \\
\text { apontados diversos fatores } \\
\text { relevantes às escolhas devido a } \\
\text { cultura, entre elas os americanos } \\
\text { possuem a menor incerteza na } \\
\text { escolha da marca, brasileiros são } \\
\text { menos hedônicos na escolha de } \\
\text { compra de seus smartphones, } \\
\text { americanos compram mais por } \\
\text { recreação, e as hipóteses de preço e } \\
\text { compra impulsiva nesse estudo não } \\
\text { foram testadas. }\end{array}$ \\
\hline $\begin{array}{l}\text { Baoku, Cuixia e Weimim } \\
\text { (2010) }\end{array}$ & $\begin{array}{l}\text { Este trabalho tem como objetivo } \\
\text { determinar estilos de tomada de } \\
\text { decisão dos consumidores chineses } \\
\text { camponeses, o método utilizado foi } \\
\text { o CSI - Consumer Style Inventory e } \\
\text { foi aplicado para } 5.827 \text { pessoas. }\end{array}$ & $\begin{array}{l}\text { A renda não tem efeitos óbvios na } \\
\text { tomada de decisão de compra de } \\
\text { aparelhos duráveis, o que } \\
\text { determina a forma de compra de } \\
\text { cada indivíduo são os fatores } \\
\text { psicológicos, e seu fator psicológico } \\
\text { também depende da sua violência } \\
\text { psicológica. }\end{array}$ \\
\hline $\begin{array}{l}\text { Thomas, Desai e Seenivasan } \\
\text { (2011) }\end{array}$ & $\begin{array}{l}\text { Esse estudo tem como objetivo } \\
\text { fazer uma análise da compra de } \\
1000 \text { famílias durante um período } \\
\text { de } 6 \text { meses para identificar as } \\
\text { diferenças entre comprar produtos } \\
\text { mais e menos saudáveis, com ou } \\
\text { sem o uso do cartão de crédito, } \\
\text { através de um experimento. }\end{array}$ & $\begin{array}{l}\text { No estudo um, foi verificado que as } \\
\text { compras das famílias analisadas } \\
\text { possuem maior quantidade de } \\
\text { produtos considerados insalubres e } \\
\text { impulsivos, quando utilizaram } \\
\text { como método de pagamento o } \\
\text { cartão de crédito ou o cartão de } \\
\text { débito. No estudo dois ao quatro, } \\
\text { levanta o questionamento sobre a } \\
\text { forma de pagamento em dinheiro } \\
\text { devido a "dor do pagamento" com a } \\
\text { relação de uma condição de menor } \\
\text { consumo impulsivo, usando tal } \\
\text { método de pagamento. }\end{array}$ \\
\hline Hsu, Chang e Chen (2012) & $\begin{array}{l}\text { A pesquisa tem por objetivo } \\
\text { investigar a relação entre as }\end{array}$ & $\begin{array}{l}\text { Foram confirmados estudos } \\
\text { anteriores que configuram o fluxo }\end{array}$ \\
\hline
\end{tabular}




\begin{tabular}{|c|c|c|}
\hline & $\begin{array}{l}\text { experiências do indivíduo com as } \\
\text { compras na internet, investigando } \\
\text { os efeitos moderadores nas } \\
\text { características do consumidor, a } \\
\text { metodologia utilizada foram } \\
\text { surveys. }\end{array}$ & $\begin{array}{l}\text { de experiências com o } \\
\text { comportamento de compra, assim } \\
\text { como características dos efeitos } \\
\text { moderadores na forma de compra } \\
\text { na rede mundial de computadores, } \\
\text { o estudo foi de forma totalmente } \\
\text { empírica, encontrando que o } \\
\text { sucesso dos sites depende da } \\
\text { habilidade de criar oportunidades } \\
\text { para que os consumidores } \\
\text { considerem fatores internos } \\
\text { individuais durante as compras na } \\
\text { internet. }\end{array}$ \\
\hline $\begin{array}{l}\text { Laude, Pattinson e Zentall } \\
\text { (2012) }\end{array}$ & $\begin{array}{l}\text { Esse artigo traz a análise de } \\
\text { comportamento de pombos com } \\
\text { referências ao comportamento dos } \\
\text { humanos através das motivações } \\
\text { de necessidade, o método utilizado } \\
\text { foi o de experimento. }\end{array}$ & $\begin{array}{l}\text { O foco do experimento é testar a } \\
\text { hipótese que o nível de motivação } \\
\text { pode influenciar na escolha da } \\
\text { escolha subótima, ou seja, o } \\
\text { comportamento do indivíduo pode } \\
\text { ser afetado dependendo da sua } \\
\text { motivação para isso, e nesse caso } \\
\text { se utilizou como exemplo } \\
\text { experimento com pombos e a sua } \\
\text { escolha para comida. }\end{array}$ \\
\hline Guo e Zhang (2012) & $\begin{array}{l}\text { Possui como foco estudar linhas de } \\
\text { produtos que estimulam a } \\
\text { deliberação do consumidor e o seu } \\
\text { comportamento de compra nessa } \\
\text { escolha, havendo ou não compra } \\
\text { impulsiva dependendo do produto. }\end{array}$ & $\begin{array}{l}\text { Foi encontrado que quando o custo } \\
\text { de deliberação é relativamente } \\
\text { baixo, a empresa deve induzir a } \\
\text { deliberação mantendo a qualidade } \\
\text { suficiente entre os seus dois } \\
\text { produtos e reduzir o seu preço do } \\
\text { produto na compra final, isso } \\
\text { motiva o consumidor a comprar o } \\
\text { produto high-end. }\end{array}$ \\
\hline $\begin{array}{l}\text { Cheng, Chuang, Wang e Kuo } \\
\text { (2013) }\end{array}$ & $\begin{array}{l}\text { O estudo realizado pelos autores } \\
\text { tem como foco identificar a } \\
\text { influência que o sexo (gênero) do } \\
\text { companheiro durante as compras, } \\
\text { pode influenciar no } \\
\text { comportamento de compras } \\
\text { impulsivas. }\end{array}$ & $\begin{array}{l}\text { No artigo foram realizados três } \\
\text { estudos: } 1 \text { - Foi examinada como a } \\
\text { companhia do comprador afeta a } \\
\text { sua decisão de compra impulsiva; } 2 \\
\text { - No segundo estudo foi adicionada } \\
\text { outra variável, a coesão de grupo, } \\
\text { para identificar se o sujeito } \\
\text { aceitaria a sugestão de compra dos } \\
\text { demais do grupo; } 3 \text { - No estudo } \\
\text { três foi estudado como a } \\
\text { suscetibilidade do sexo oposto } \\
\text { pode influenciar na escolha de } \\
\text { compra impulsiva. Foi descoberto } \\
\text { com o estudo que mulheres } \\
\text { acompanhadas de homens são mais } \\
\text { suscetíveis a compra por } \\
\text { impulsivo, a interação é um } \\
\text { importante fator na decisão de } \\
\text { compra impulsiva e pessoas que } \\
\text { possuem maior força de influência } \\
\text { de terceiros podem apresentar } \\
\text { maiores características de compra } \\
\text { impulsiva que os demais } \\
\text { compradores. }\end{array}$ \\
\hline Yousaf e Malik (2013) & $\begin{array}{l}\text { O objetivo do estudo é identificar e } \\
\text { compreender a conexão entre a }\end{array}$ & $\begin{array}{l}\text { No estudo foi identificado que o } \\
\text { comportamento do consumidor }\end{array}$ \\
\hline
\end{tabular}




\begin{tabular}{|c|c|c|}
\hline & $\begin{array}{l}\text { aceitação da religiosidade e o } \\
\text { envolvimento do produto com o } \\
\text { consumidor a partir de vários } \\
\text { constructos do comportamento do } \\
\text { consumidor. Para a realização do } \\
\text { estudo, foram aplicados } 225 \\
\text { questionários para a categoria com } \\
\text { alto envolvimento com o produto, e } \\
150 \text { para a categoria com baixo } \\
\text { envolvimento com o produto. }\end{array}$ & $\begin{array}{l}\text { varia de acordo com o seu } \\
\text { envolvimento e aceitação da } \\
\text { religiosidade, onde que o grupo } \\
\text { com menor religiosidade foi } \\
\text { identificada a maior impulsividade } \\
\text { nas suas compras, e para } \\
\text { consumidores com maior nível de } \\
\text { religiosidade, apelos de anúncios } \\
\text { não foram levados em conta para o } \\
\text { seu comportamento de compra, } \\
\text { tendo comportamento de compra } \\
\text { menos impulsivo. Consumidores } \\
\text { com maior nível de religiosidade } \\
\text { foram considerados mais racionais } \\
\text { perante o seu comportamento de } \\
\text { compra, resultados semelhantes } \\
\text { foram encontrados no estudo de } \\
\text { Sood e Nasu (1995). }\end{array}$ \\
\hline $\begin{array}{l}\text { Hubert, Florack, Linzmajer e } \\
\text { Kenning (2013) }\end{array}$ & $\begin{array}{l}\text { O presente estudo visou } \\
\text { compreender como as percepções } \\
\text { sobre a embalagem do produto } \\
\text { afetam as tendências de compra } \\
\text { impulsiva, para isso foi utilizado o } \\
\text { método de ressonância magnética } \\
\text { funcional. }\end{array}$ & $\begin{array}{l}\text { Foram encontradas diferenças nas } \\
\text { reações dos compradores ao } \\
\text { analisarem embalagens neutras de } \\
\text { embalagens atraentes, associadas } \\
\text { ao sistema impulsivo e reflexivo, ou } \\
\text { seja, foi encontrado que há de fato } \\
\text { uma relação com as fortes } \\
\text { tendências de compra impulsiva, e } \\
\text { as atividades do cérebro associadas } \\
\text { com processos impulsivos e } \\
\text { reflexivos. }\end{array}$ \\
\hline Lucas e Koff (2014) & $\begin{array}{l}\text { O estudo foi aplicado com } 232 \\
\text { estudantes mulheres do ensino } \\
\text { superior, e visa examinar o papel } \\
\text { da impulsividade em três aspectos } \\
\text { da compra impulsiva, para isso } \\
\text { utilizou-se a escala IBT, através de } \\
\text { surveys. }\end{array}$ & $\begin{array}{l}\text { O resultado do estudo comprovou } \\
\text { uma alta evidência de relação entre } \\
\text { o UPPS-P e os distintos aspectos da } \\
\text { compra impulsiva. Ao contrário das } \\
\text { expectativas, a dimensão afetiva } \\
\text { não teve uma relação direta com a } \\
\text { forma de comportamento de } \\
\text { compra impulsivo, o estudo teve } \\
\text { como foco também a identificação } \\
\text { pela parte dos estudados sobre a } \\
\text { auto percepção do comportamento } \\
\text { impulsivo. }\end{array}$ \\
\hline $\begin{array}{l}\text { Sharma, Sivakumaran e } \\
\text { Marshall (2014) }\end{array}$ & $\begin{array}{l}\text { O trabalho visa estudar o risco da } \\
\text { compra por impulso, fazendo dois } \\
\text { estudos. Para isso, primeiro com } \\
\text { questionários e o segundo com um } \\
\text { experimento em laboratório. }\end{array}$ & $\begin{array}{l}\text { Demonstrou que há uma forte } \\
\text { relação da compra com as compras } \\
\text { impulsivas realizadas pelos } \\
\text { participantes. }\end{array}$ \\
\hline
\end{tabular}

Fonte: Elaborado pelos autores 